\title{
Technological detergents for cleaning compressors of gas turbine installations
}

\author{
Galina Prokofieva ${ }^{1}$, Nina Belousova ${ }^{2}$, Margaryta Berkut ${ }^{1}$, Oleksii Klimenkov ${ }^{1}$ \\ 1. Department of Technology of Inorganic substances, Water Treatment and General chemical technology, \\ National Technical University of Ukraine «Igor Sikorsky Kyiv Polytechnic Institute», UKRAINE, Kyiv, Peremogy \\ Avenue 37, education building №4, E-mail: margo.berkut.00@ gmail.com
}

2. Department of Electrochemical Production Technology, National Technical University of Ukraine «Igor Sikorsky Kyiv Polytechnic Institute», UKRAINE, Kyiv, Peremogy Avenue 37, education building №4.

\begin{abstract}
The prospects of using technical detergents to solve environmental and energy saving problems in the operation of compressor equipment are studied. The results of physical and chemical studies of the interaction of environmentally safety technical detergents developed by us with components of technological contamination of compressors are presented, which contributes to their reliability and durability of operation.
\end{abstract}

Keywords -cleaning, detergent, compressor equipment, ecology, surfactants.

\section{Introduction}

During the operation of compressor equipment, its technical condition and characteristics gradually deteriorate, which is associated with operational and technological contamination of the internal and external surfaces of gas transmission system elements. The gradual accumulation of dirt leads to an increase in energy consumption, a decrease in the power of equipment, its reliability and durability of operation.

To solve these problems, environmentally friendly cleaning of equipment elements from contamination remains relevant, which in turn requires the development of effective technical detergents.

\section{Research materials}

One of the promising methods of cleaning compressor equipment is physico-chemical using solutions of technical detergents (TD). The choice of TD composition is preceded by a study of the composition of technological contaminants. The studies were carried out using various physical and chemical methods: thermographic, radiographic, spectral, spectrophotometric, electron paramagnetic resonance, infrared spectroscopy, polarization resistance, etc.

The results of analyses of contamination of the surfaces of gas turbine units of main gas transmission systems showed the presence of organic and inorganic compounds in them. It should be particularly noted that the predominant component of pollutants is iron, the presence of which contributes to the possibility of corrosion and erosion processes during the operation of compressor equipment.

The main components of TD that ensure its effectiveness are surfactants. We considered a wide range of surfactants of different classes, among which non-ionic surfactants with significant dispersing and emulsifying properties showed the greatest effectiveness. Special attention was paid to the study of the ratio of nonionic surfactants to Iron (III) ions which used by TD in alkaline environments, contribute to the reverse deposition of solid sediment of iron-containing compounds on the cleaned surface of equipment, which significantly reduces the effectiveness of TD.

Therefore, the physico-chemical study of the interaction in the "Fe (III) - neoinogenic surfactant" system in an aqueous solution aroused interest. For this purpose, the concentration and acid-base conditions of interaction of Fe (III) ions with a number of nonionic pairs were studied. 
The results of spectrophotometric studies showed the possibility of complex formation processes in the studied systems. Mathematical processing of the obtained results made it possible to establish the composition of complex compounds and the mechanism of their formation. It was experimentally proved that the obtained concentration conditions of complex implementation in the system "pollution component - TD component" is responsible for the greatest efficiency of technological detergent, therefore, can be based on the choice according to the assigned TD.

An important characteristic of technical detergents is its anti-corrosion properties which are provided by the introduction of special impurities in them that counteract corrosion processes both for cleaning from technological contamination and for insufficient flushing of gas turbine units from TD residues. It should be noted that the introduction of anti-corrosive impurities increases the salt content of technical detergents that negatively affects the environmental friendliness of the product.

We considered the possibility of reducing the corrosion activity of TD by using nonionic surfactants with multifunctional action. Positive results were obtained, which were confirmed by industrial tests.

\section{Conclusions}

The composition of technical pollution of compressor equipment elements has been studied by various physicochemical methods. The interaction in aqueous solutions of the systems "Fe (III) - nonionic surfactants", the results of which are the basis for the development of compositions of technical detergents. The anticorrosive properties of the developed ecologically safe TD on the basis of nonionic pairs of semifunctional action are established.

\section{References}

1. Abramzon L.A. Surfactants. Properties and application. Leningrad: Khimiya, 1981. [In Russian]

2. Corrosion resistance of chemical process equipment. Corrosion under the influence of coolants, refrigerants and working fluids. Ref. Izd. / A.M. Sukhotin, A.F. Bagachev, V.G. Polish et al. / Ed. A.M. Sukhotina. V.M. Barenbilt. Leningrad: Khimiya, 1988. [In Russian]

3. Prokofieva G., Belousova N., Bilenko N. The study of anti-corrosion ingredients in technical detergents. VIII International Conference" Problems of Corrosion and Corrosion Protection of Structural Materials Physicomechanical Institute named by G. Karpenko NASU. 68 June, Lviv, 2006. [In Ukrainian]

4. Shtupel G. Synthetic detergents and cleaners. Moscow: Gosudarstvennoe scientific tehniçeskoe izdatel’stvo himiçeskoy literaturı 1960 [In Russian] 